\title{
Characteristics of atmospheric circulation patterns over East Asia and their impacts on precipitation in summer
}

\author{
Shuping Lii ${ }^{1}$, Guolin Feng ${ }^{2,3, *}$, Wei Hou ${ }^{3}$, Jianbo Cheng ${ }^{4}$ \\ ${ }^{1}$ College of Hydraulic Science and Engineering, Yangzhou University, Yangzhou 225000, PR China \\ ${ }^{2}$ College of Physical Science and Technology, Yangzhou University, Yangzhou 225000, PR China \\ ${ }^{3}$ National Climate Center, China Meteorological Administration, Beijing 100081, PR China \\ ${ }^{4}$ College of Atmospheric Sciences, Lanzhou University, Lanzhou 730000, PR China
}

\begin{abstract}
We investigated 3 summer atmospheric circulation patterns over the mid-latitudes of East Asia - the monopole (MOP), East Asia-Pacific (EAP) and southeast-northwest out-of-phase dipole (EWD) - and their impacts on precipitation in eastern China. Our results show that an increase in the frequency of the positive MOP pattern enhances precipitation in northeastern China, while a longer persistence of this pattern induces above-average precipitation in the midto-lower reaches of the Yangtze River valley (MLRYR). For the negative MOP pattern, a higher frequency of this pattern leads to below-average precipitation in northeastern and southern China, while its persistence has insignificant influences on precipitation in eastern China. Increases in the frequency and persistence of the positive EAP pattern intensify precipitation in the MLRYR. For the negative EAP pattern, increases in the frequency and persistence of the pattern reduce precipitation in the MLRYR, and a higher frequency of this pattern markedly intensifies precipitation in northern China. Regarding the positive EWD pattern, an increase in its frequency favors below-average precipitation in northern China, and an increase in its persistence clearly intensifies precipitation in the MLRYR. Increases in the frequency and persistence of the negative EWD pattern produce below- (above-)average precipitation in the MLRYR (northeastern China), with a longer persistence of this pattern especially reducing precipitation in the MLRYR. These results indicate that the frequency and persistence of each pattern have different impacts on precipitation in eastern China.
\end{abstract}

KEY WORDS: Eastern China $\cdot$ Atmospheric circulation patterns $\cdot$ Summer precipitation

\section{INTRODUCTION}

Eastern China, which includes the 4 subregions of northeastern China - northern China, the mid-tolower reaches of the Yangtze River valley (MLRYR) and southern China - is a typical monsoon area and an agricultural and economic center of national significance (Fig. 1). Highly frequent climatic disasters, especially wide-ranging drought and flooding, have caused serious economic losses after the late 1970s, which account for approximately $2.7 \%$ of the annual

${ }^{*}$ Corresponding author: fenggl@cma.gov.cn gross national product (Huang et al. 2006). Against the background of global warming since the 1980s, extreme weather and climate events have been occurring more frequently (Lin et al. 2004, Ren et al. 2004), resulting in even more serious economic losses. Two consecutive rainfall events in late June 2015 associated with an intensified western Pacific subtropical high (WPSH) led to widespread flooding in eastern China (Wang \& Gu 2016). Since the 1950s, the north-south dipole pattern of annual precipitation in eastern China, referred to as the 'southern

(C) The authors 2019. Open Access under Creative Commons by Attribution Licence. Use, distribution and reproduction are unrestricted. Authors and original publication must be credited. 


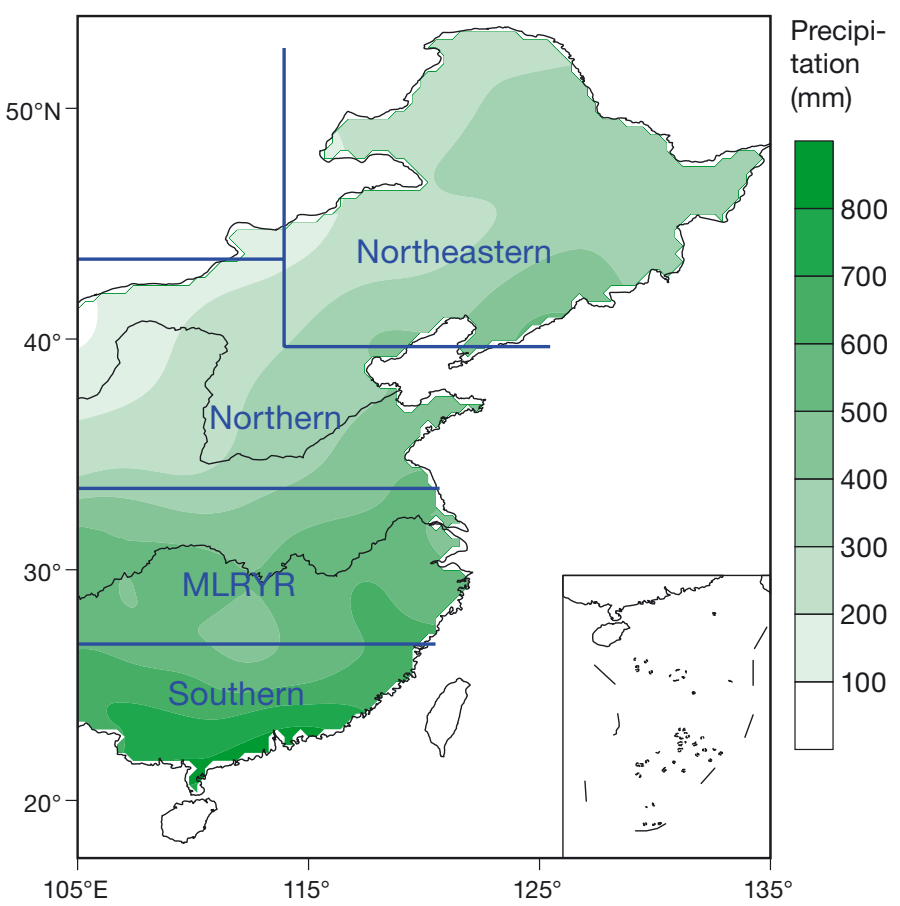

Fig. 1. Climatology of summer precipitation in eastern China, with the 4 subregions of northeastern China, northern China, the mid-to-lower reaches of the Yangtze River valley (MLRYR), and southern China marked

flooding and northern drought' pattern, has shown clear decadal variation (Yang et al. 2017), and a continuous decline in the mean precipitation has caused a shift from wet to dry conditions in northeastern and northern China (Ma \& Fu 2006). Barriopedro et al. (2012) showed that the drought episode from May 2009 to April 2010 in northern China had serious effects on the water supply for human activities. Zhai et al. (2005) indicated that an increase in high-intensity summer precipitation events in the MLRYR resulted in more frequent flooding during the period of 1951-2000. Chen et al. (2017) proposed that summer precipitation in southern China clearly increased in the early 1990s. These studies demonstrated that precipitation in eastern China has obvious temporal and spatial variability.

Precipitation is strongly related to water vapor transport and its intensity, which are induced by atmospheric circulation and transient eddies, and atmospheric circulation plays an important role in water vapor transport (Pokam et al. 2012). The WPSH greatly influences the summer precipitation distribution in China because it directly dominates the water vapor transport from the South China Sea (SCS) and western Pacific to eastern China (Liu \& Wu 2004). Moreover, the summer rainbelt moves from southern
China, the Yangtze River valley and to northern China, and this northward migration of precipitation corresponds to the northward shifts of the WPSH (Tao \& Xu 1962, Ding 1992). Liu et al. (2015) indicated that the North Atlantic Oscillation (NAO) controls the summer precipitation dipole oscillation in the Tibetan Plateau, mainly by modifying atmospheric circulation and then producing anomalous water vapor transport. Nitta (1987) found a northsouth dipole pattern in summer over the western Pacific and named it the Pacific-Japan teleconnection pattern, and Huang \& Li (1987) indicated a tripole teleconnection pattern over the East AsiaPacific sector, and named it the East Asia-Pacific (EAP) teleconnection pattern. In fact, these 2 patterns point to the same phenomenon in that they are both excited by anomalous convection in the tropical western Pacific (hereafter referred to as the EAP pattern). A positive EAP pattern produces an anomalous anticyclone over the SCS and an anomalous cyclone in Japan, contributing to the anomalous moisture convergence that intensifies summer precipitation in the MLRYR (Huang 2004).

Anomalous atmospheric circulation patterns that last for consecutive months have dramatic effects on total precipitation amounts and, consequently, on subsequent drought or flooding risks (e.g. Ren et al. 2013, Screen \& Simmonds 2014, Wise \& Dannenberg 2014). The frequency and persistence of atmospheric circulation anomalies cause abnormal precipitation - for example, Petrow et al. (2009) demonstrated that significant increases in the frequency and persistence of circulation patterns associated with above-average precipitation contributed to flooding in Germany in winter. Swain et al. (2016) found that a robust increase in the persistence of a high ridge near the west coast of North America during the cold season resulted in an amplification of the background state. The Urals blocking was more persistent during 2000-2013 than during 1979-1999, causing frequent severe cold events over East Asian countries (Honda et al. 2009, Luo et al. 2016). Wang \& Chen (2014) indicated that strong Urals blocking enhanced the East Asia winter monsoon during 2004-2012, which is associated with frequent cold winters over East Asia. The establishment and retreat of the Okhotsk high is closely linked to summer precipitation in eastern China (Zhang \& Tao 1998). The occurrence of a double blocking high over the Urals and Sea of Okhotsk in summer is a typical precursor circulation pattern for extreme precipitation in centraleastern China (Chen \& Zhai 2014). In January 2008, a persistent blocking high over Siberia favored the 
southward expansion of northerly flows, which converged with the persistent southwesterly winds from the Bay of Bengal to southern China, leading to cold temperatures and anomalous snow cover in southern China (Zhou et al. 2009). Therefore, as these results indicate, it is necessary to investigate the impacts of the frequency and persistence of circulation patterns on summer precipitation in eastern China.

Previous studies have contributed to the investigation of atmospheric circulation patterns and their connections with surface meteorological conditions (e.g. Notaro et al. 2006, Diao et al. 2015, Zhang et al. 2016). Duckstein et al. (1993) investigated the relationship between large-scale circulation patterns and flooding in small- to moderate-sized river basins. Kyselý (2007) described the atmospheric circulation patterns over Europe using the Hess-Brezowsky catalog, and investigated the impacts of changes in the mean persistence of different circulation patterns on the frequency and severity of warm and cold extremes over central Europe. Much effort has also been made to investigate atmospheric circulation patterns over East Asia (e.g. Sun et al. 2015, Xie \& Bueh 2015, Li et al. 2016). Wang et al. (2016) applied empirical orthogonal function analysis to 30-60 d filtered and normalized $500 \mathrm{hPa}$ geopotential height anomalies over the region (encompassed by $0-80^{\circ} \mathrm{N}$, $100-160^{\circ} \mathrm{E}$ ) during the boreal summer and found that the first leading mode is a well-organized tripole pattern but explains only $18 \%$ of the total variance. Wu (2002) indicated that the leading mode of the summer $200 \mathrm{hPa}$ horizontal wind anomaly fields over 20$60^{\circ} \mathrm{N}, 30-170^{\circ} \mathrm{E}$ explains approximately $23 \%$ of the total variance. Although the leading mode of atmospheric circulation over East Asia can be well separated from the other modes, most of the circulation variability is not captured because of the complex spatial structures encompassing the tropics, subtropics and mid-latitudes.

In recent studies, the mid-latitude continents of the Northern Hemisphere have been divided into 7 regions (Screen \& Simmonds 2014, Chen et al. 2016): western North America $\left(35-60^{\circ} \mathrm{N}, 150-115^{\circ} \mathrm{W}\right)$, central North America $\left(35-60^{\circ} \mathrm{N}, 115-80^{\circ} \mathrm{W}\right)$, eastern North America $\left(35-60^{\circ} \mathrm{N}, 80-45^{\circ} \mathrm{W}\right)$, Europe (35$\left.60^{\circ} \mathrm{N}, 15^{\circ} \mathrm{W}-25^{\circ} \mathrm{E}\right)$, western Asia $\left(35-60^{\circ} \mathrm{N}, 25-\right.$ $\left.65^{\circ} \mathrm{E}\right)$, central Asia $\left(35-60^{\circ} \mathrm{N}, 65-105^{\circ} \mathrm{E}\right)$ and eastern Asia $\left(35-60^{\circ} \mathrm{N}, 105-145^{\circ} \mathrm{E}\right)$. Horton et al. (2015) detected the atmospheric circulation patterns over these 7 mid-latitude regions of the Northern Hemisphere using self-organizing map cluster analysis. Furthermore, as frontal precipitation accounts for a large proportion of the summer precipitation in east- ern China, the atmospheric circulation in the mid-latitudes, which can be characterized in terms of synoptic patterns, is indeed important for investigating summer precipitation in eastern China. Therefore, $35-60^{\circ} \mathrm{N}, 105-145^{\circ} \mathrm{E}$ is a compelling area in which to explore atmospheric circulation patterns of East Asia associated with regional precipitation. From this perspective, we investigated the summer atmospheric circulation patterns over the mid-latitudes of East Asia, and further clarified the impacts of the frequency and persistence of each pattern on precipitation in eastern China.

\section{DATA AND METHODS}

The daily and monthly geopotential height, surface pressure, horizontal winds and specific humidity data for 1961-2015 were obtained from the National Centers for Environmental Prediction/National Center for Atmospheric Research (NCEP/NCAR) and have a $2.5 \times 2.5^{\circ}$ horizontal resolution (Kalnay et al. 1996). Monthly precipitation data at 1493 stations (excluding stations with missing values) in China for the period 1961-2015 were obtained from the China Meteorological Administration, and were interpolated to a $0.5 \times 0.5^{\circ}$ horizontal resolution using Cressman's method (Cressman 1959). The results of this study are based mainly on the period 1961-2015. Summer refers to June, July and August (JJA), and the summer mean refers to the average from JJA. Trends of the geopotential height anomalies in the Northern Hemisphere due to global warming alter atmospheric circulation patterns; therefore, the conclusions in this study are based on the reanalysis and observational data after removing the linear trends. Statistical significance was assessed using a 2-tailed Student's $t$-test. The monthly Arctic Oscillation (AO), NAO and East Atlantic-West Russia (EAWR) teleconnection pattern indices were obtained from the NOAA's Climate Prediction Center. The monthly EAP (Huang 1992) pattern index was calculated according to the following equation, where $Z$ represents the normalized monthly $500 \mathrm{hPa}$ geopotential height anomalies:

$$
\begin{aligned}
\mathrm{EAP}= & \frac{1}{3} Z\left(20^{\circ} \mathrm{N}, 120^{\circ} \mathrm{E}\right)-\frac{1}{3} Z\left(37.5^{\circ} \mathrm{N}, 120^{\circ} \mathrm{E}\right) \\
& +\frac{1}{3} Z\left(60^{\circ} \mathrm{N}, 120^{\circ} \mathrm{E}\right)
\end{aligned}
$$

The vertically integrated water vapor transport flux was calculated based on the following equation (Smirnov \& Moore 1999), where $g$ is gravity acceler- 
ation, $P_{\mathrm{s}}$ refers to the surface pressure (units: $\mathrm{hPa}$ ), $q$ is the specific humidity (units: $\mathrm{g} \mathrm{kg}^{-1}$ ), and $V$ is the horizontal wind velocity (units: $\mathrm{m} \mathrm{s}^{-1}$ ):

$$
Q=-\frac{1}{g} \int_{P_{s}}^{300} q V d p
$$

The $k$-means clustering method is a common technique for categorizing multiple individual samples into several clusters (Spath 1985), and we calculated the centroid of each cluster through the squared Euclidian distance. Generally, the squared Euclidian distance of an $n \times p$ matrix, $\boldsymbol{X}$, is defined as:

$$
d_{i j}=\left[\sum_{k=1}^{p}\left(x_{i k}-x_{j k}\right)^{2}\right]^{1 / 2}
$$

where $n$ is the number of observations and $p$ is the number of variables $\left(i=1,2, \ldots \mathrm{n}_{i} j=1,2, \ldots, \mathrm{n}\right)$. This equation stands for the distance between $2 p$-dimensional points in Euclidian space. Additionally, the number of clusters needs to be determined in advance, and the sum of distances over all clusters from each point to its cluster centroid is minimized repetitively. To separate the clusters well, the points are moved between clusters until the sum cannot be decreased further.

The $k$-means clustering algorithm is suitable for huge amounts of data, and has been applied to different atmospheric data sets. In this study, the $k$-means clustering algorithm was applied to the daily $500 \mathrm{hPa}$ geopotential height to categorize circulation patterns over the mid-latitudes of East Asia, and the atmospheric circulations were classified into 6 groups, which correspond to the positive and negative phases of the 3 circulation patterns. To investigate the features of the circulation patterns, we counted the total number of days on which each circulation pattern occurred ('occurrence'; days), the total number of consecutive occurrences ('frequency'; number) and the longest consecutive occurrence ('maximum duration'; days). To clarify the different influences of the frequency and persistence of each pattern, the maximum duration, in some sense, is more suitable for representing the persistence of each pattern than is the mean duration (hereafter, the maximum duration is referred to as persistence).

\section{SUMMER ATMOSPHERIC CIRCULATION PATTERNS AND THEIR FEATURES}

The $k$-means clustering algorithm was applied to the daily standardized $500 \mathrm{hPa}$ geopotential height over the mid-latitudes of East Asia during 19612015, and we categorized the summer atmospheric circulations into 6 groups (Fig. 2). Fig. 3 shows the composite maps of the daily geopotential height anomalies for these circulation patterns. Group 1 features a monopole (MOP) pattern of positive anomalies, which explains $30.1 \%$ of the total variance; its corresponding atmospheric circulation pattern is defined as the positive MOP pattern (Figs. 2a \& 3a). Group 2, which accounts for $6.7 \%$ of the total variance, presents negative anomalies over the mid-latitudes of East Asia and is defined as the negative MOP pattern (Figs. 2b \& 3b). Group 3 explains $9.5 \%$ of the total variance, and its spatial pattern is very similar to the positive EAP pattern (Figs. 2c \& 3c). Moreover, group 4 explains $25.5 \%$ of the total variance and resembles the negative EAP pattern (Figs. 2d \& 3d); therefore, we define groups 3 and 4 as the EAP pattern. Groups 5 and 6 feature a southeast-northwest out-of-phase dipole (EWD) pattern and are referred to as the positive and negative phase of the EWD pattern, respectively (Figs. 2e,f \& $3 \mathrm{e}, \mathrm{f})$. The positive EWD pattern explains $14.7 \%$ of the total variance, while the negative EWD pattern accounts for $13.5 \%$. Consequently, we categorized atmospheric circulations over the mid-latitudes of East Asia into 3 patterns - the MOP pattern, EAP pattern and EWD pattern.

To further investigate the spatial distribution of the 6 group circulation patterns on the climatological time scale, we projected the standardized summer $500 \mathrm{hPa}$ geopotential height onto the 6 group circulation patterns and obtained their corresponding indices to describe the temporal variability. The atmospheric circulations associated with the group 1 and group 2 circulation pattern indices feature an anomalous center over East Asia (Fig. 4a,b), and are obviously different from the conventional teleconnection patterns in the Northern Hemisphere (Wallace \& Gutzler 1981). The $500 \mathrm{hPa}$ geopotential height anomaly fields associated with the group 3 and group 4 circulation indices obviously resemble the EAP pattern, and the correlation coefficients between their indices and the EAP pattern index are 0.79 and -0.78 , respectively, which are significant at the $99 \%$ confidence level using a 2-tailed Student's $t$ test. These results further verify that the group 3 and group 4 circulation patterns capture the features of the EAP pattern well (Fig. 4c,d). The $500 \mathrm{hPa}$ geopotential height anomaly centers associated with the group 5 and group 6 circulation pattern indices are similar to those of the EAWR pattern (Fig. 4e,f). Moreover, the temporal correlation coefficients between these 2 group circulation pattern indices and the EAWR pattern index are significant at the $90 \%$ 
(a) Group $130.1 \%$

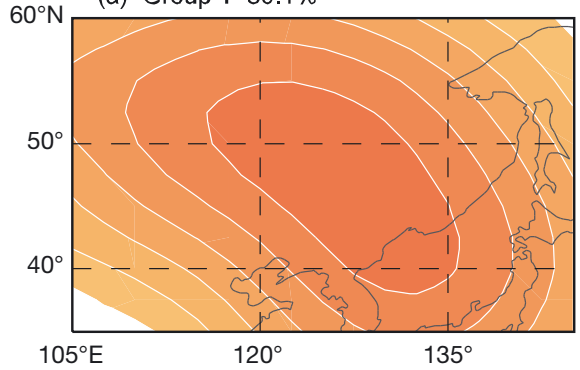

(b) Group $2 \quad 6.7 \%$ (c) Group $39.5 \%$

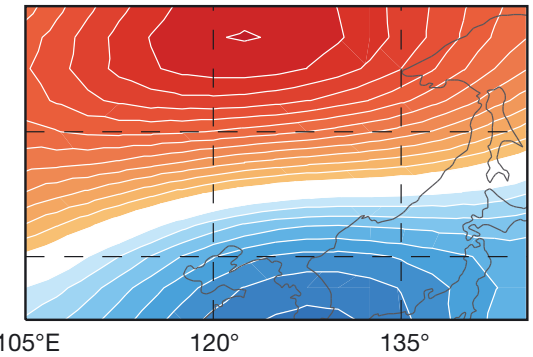

(d) Group $425.5 \%$ (e) Group 5 14.7\%

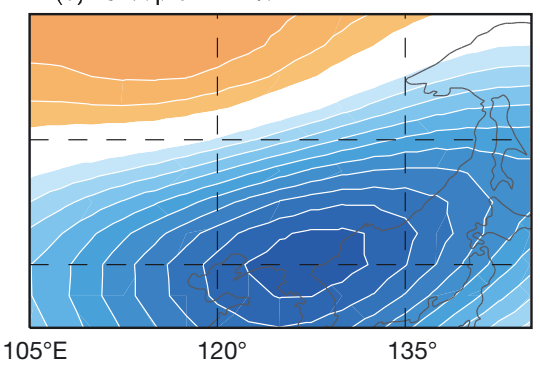

(f) Group 6 13.5\%
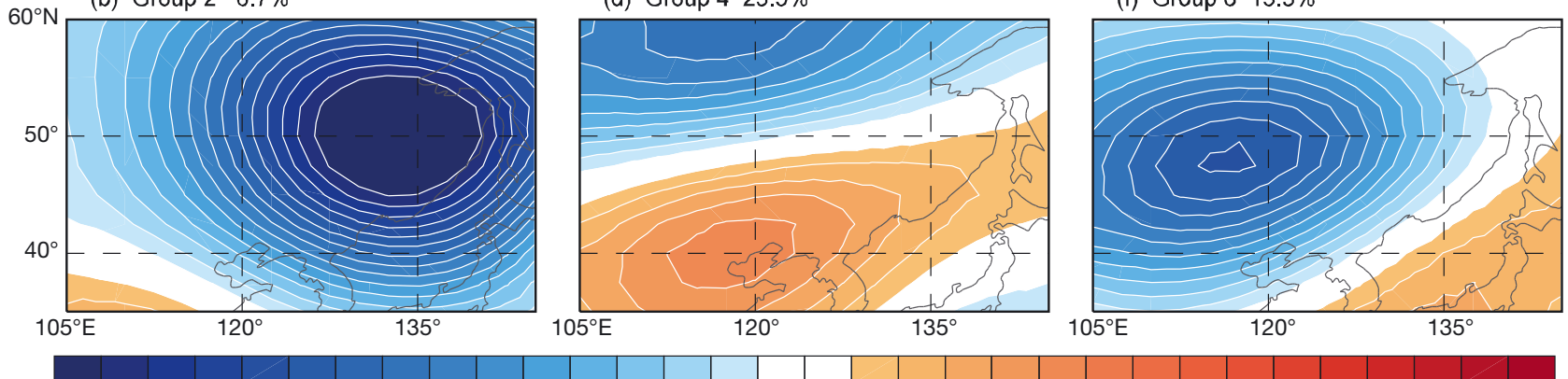

$105^{\circ} \mathrm{E}$

$120^{\circ}$

$105^{\circ} \mathrm{E}$

$120^{\circ}$

135

$-1.5$

$-1.3-1.1$

$500 \mathrm{hPa}$ geopotential height anomaly

Fig. 2. The $k$-means clustering algorithm-derived summer circulation patterns (standardized $500 \mathrm{hPa}$ geopotential height, unitless) corresponding to the $(a, c, e)$ positive and $(b, d, f)$ negative phase of the 3 circulation patterns, respectively. (a,b) Monopole (MOP) pattern, $(\mathrm{c}, \mathrm{d})$ East Asia-Pacific (EAP) pattern, $(\mathrm{e}, \mathrm{f})$ southeast-northwest out-of-phase dipole (EWD) pattern. Numbers at the top indicate explained variance
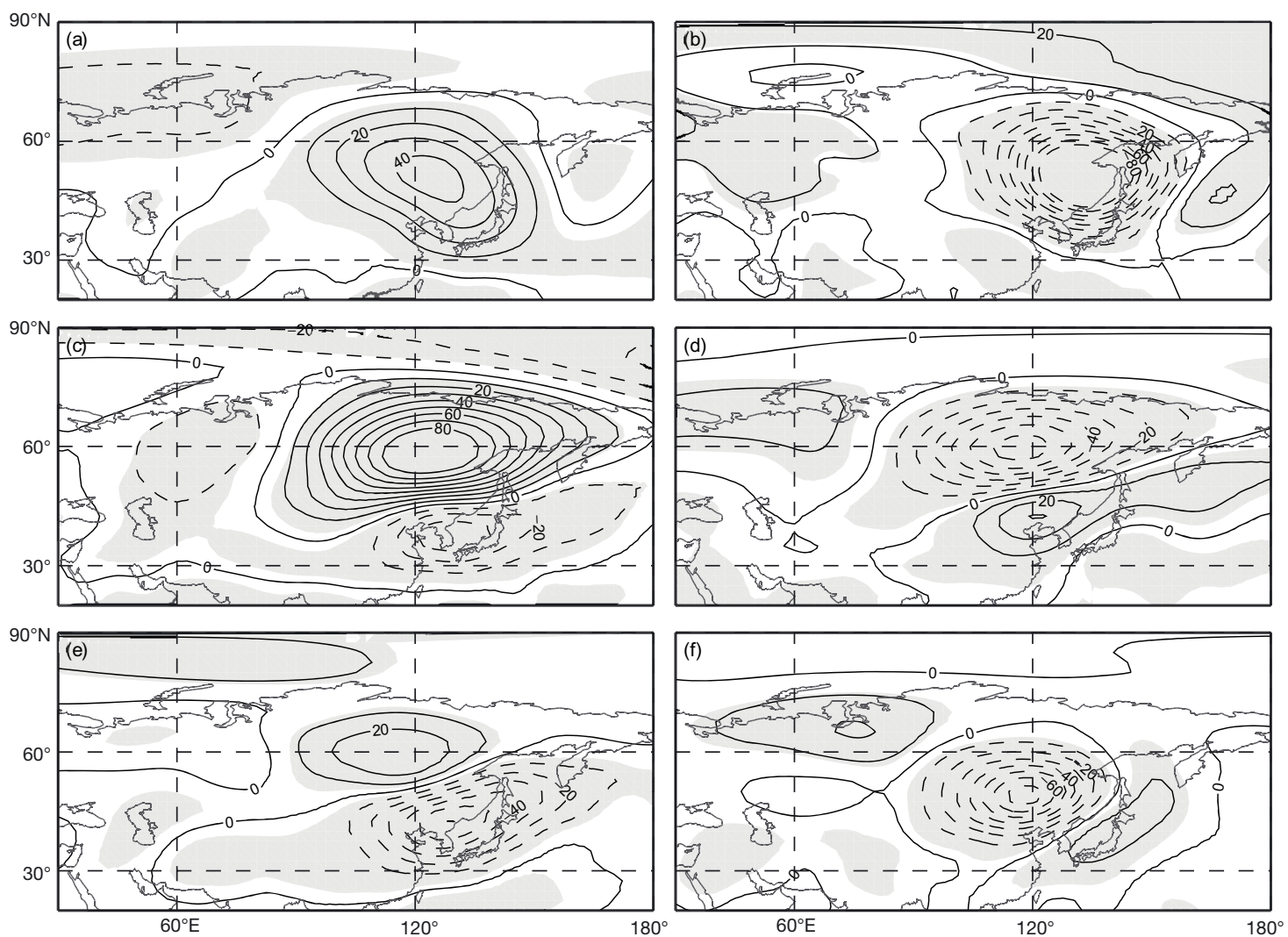

Fig. 3. Composite daily $500 \mathrm{hPa}$ geopotential height anomalies (units: $\mathrm{m}$ ) for the (a) positive Monopole (MOP), (b) negative MOP, (c) positive East Asia-Pacific (EAP), (d) negative EAP, (e) positive southeast-northwest out-of-phase dipole (EWD), and (f) negative EWD patterns. Shaded areas exceed the $95 \%$ confidence level using a 2-tailed Student's $t$-test 

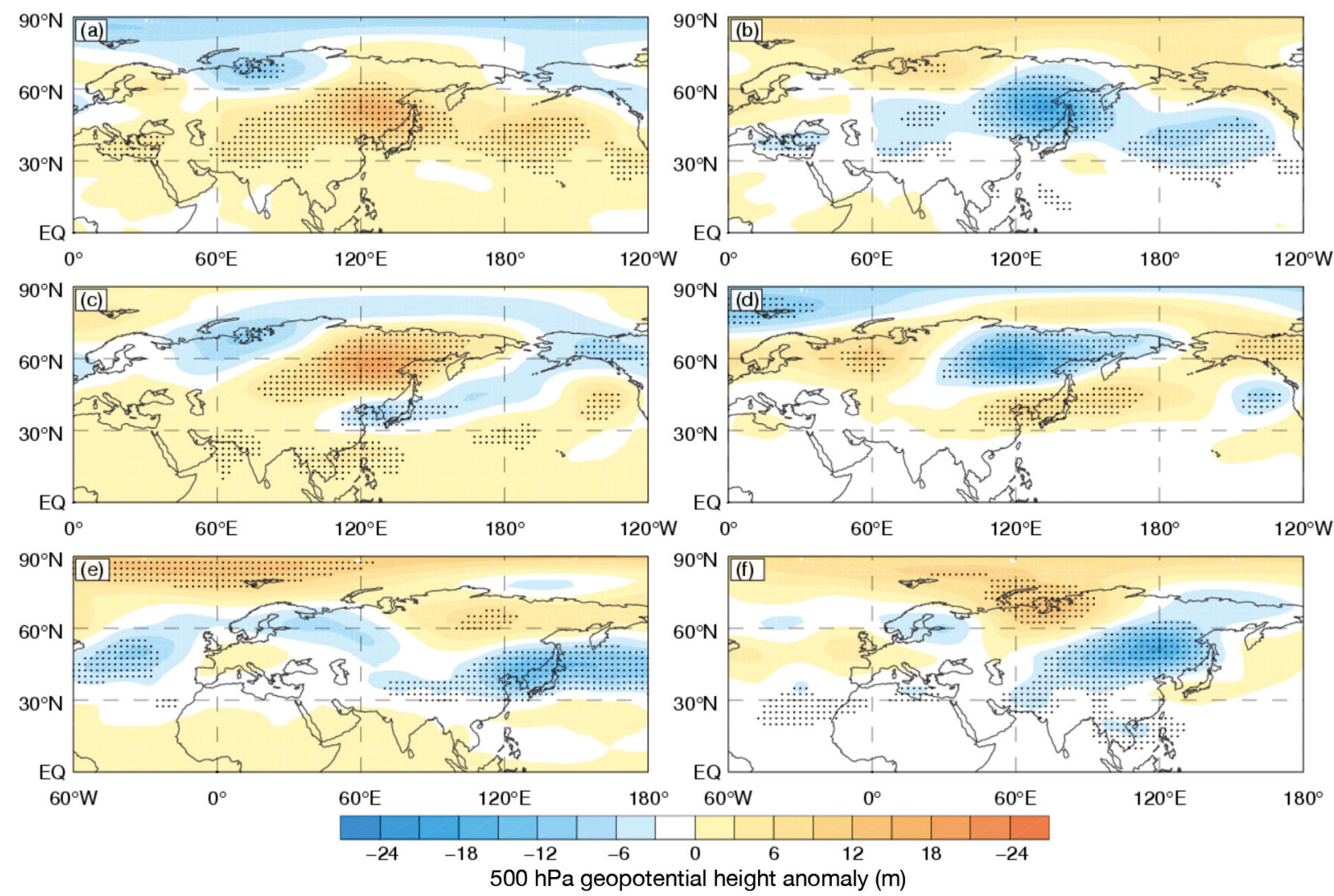

Fig. 4. Regression of summer $500 \mathrm{hPa}$ geopotential height anomalies onto the 6 group circulation pattern indices: (a) Group 1, (b) Group 2, (c) Group 3, (d) Group 4, (e) Group 5 and (f) Group 6. Dotted areas indicate the $95 \%$ confidence level using a 2-tailed Student's $t$-test

confidence level. These indicate that the EWD pattern is also referred to as the EAWR-like pattern. For convenience, hereafter, the 6 group circulation patterns are referred to as the positive/negative MOP, EAP and EWD patterns; the main abbreviations used in this study are listed in Table 1.

The occurrence, frequency and persistence of each pattern show remarkable interannual variability and obvious asymmetry (Fig. 5). The occurrence of the positive MOP pattern is much higher than that of the negative MOP pattern (Fig. 5a,b), while the occurrence of the negative EAP pattern is greater than that of the positive EAP pattern (Fig. 5c,d). There are no obvious differences between the positive and nega- tive EWD pattern occurrences (Fig. 5e,f). Note that the higher occurrence of the negative EWD pattern mainly happened before the 1990s. According to the definition of the occurrence, frequency and persistence in Section 2, these 3 time series of each pattern are correlated with each other. The occurrence of each pattern is significantly correlated with its frequency and persistence at the $99 \%$ confidence level using a 2-tailed Student's t-test (Table 2). The correlation coefficient between the frequency and persistence of each pattern is $<0.6$ or insignificant, indicating that the frequency and persistence of each pattern are relatively independent and reflect different features in some sense. A linear regression

Table 1. Abbreviations list for the atmospheric circulation patterns and the regions

\begin{tabular}{|c|c|c|c|}
\hline Abbreviation & Pattern/region & Abbreviation & Pattern/region \\
\hline MOP & Monopole & $\mathrm{AO}$ & Arctic Oscillation \\
\hline EAP & East Asia-Pacific & NAO & North Atlantic Oscillation \\
\hline EWD & Southeast-northwest out-of-phase dipole & MLRYR & Mid-to-lower reaches of the Yangtze River valley \\
\hline EAWR & East Atlantic-West Russia & SCS & South China Sea \\
\hline
\end{tabular}



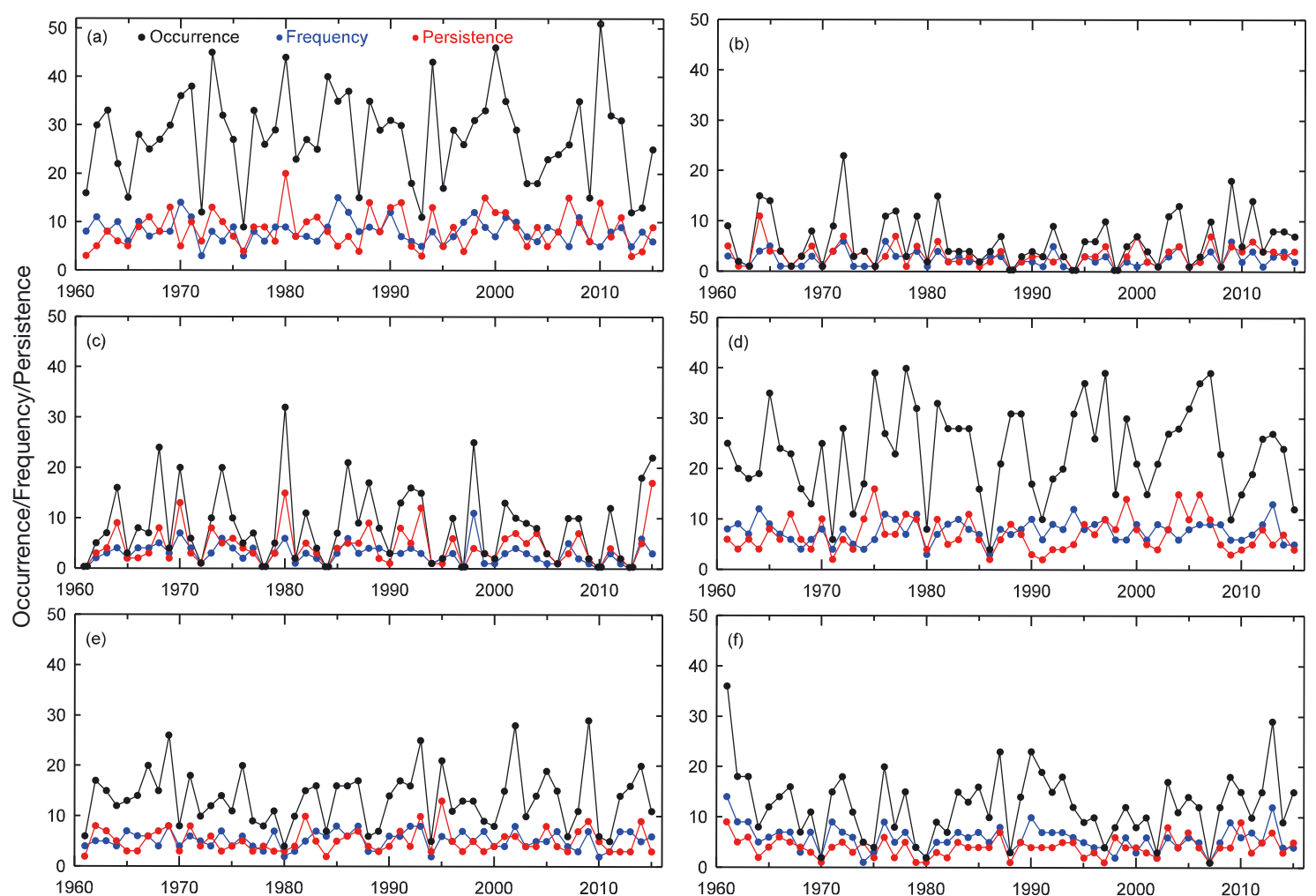

Fig. 5. Time series of the occurrence, frequency and persistence of the (a) positive monopole (MOP), (b) negative MOP, (c) positive East Asia-Pacific (EAP), (d) negative EAP, (e) positive southeast-northwest out-of-phase dipole (EWD) and (f) negative EWD patterns

method was applied to identify the impacts of the frequency and persistence of each pattern on precipitation in eastern China in the following section.

\section{IMPACTS OF ATMOSPHERIC CIRCULATION PATTERNS ON SUMMER PRECIPITATION}

\subsection{MOP pattern}

We further investigated summer atmospheric circulations and their connections with precipitation in eastern China from the perspective of the frequency and persistence of each pattern. An increase in the frequency of the positive MOP pattern induces a significant positive anomaly center over the midlatitudes of East Asia, which presents a southeastnorthwest oriented feature (Fig. 6a). The longer persistence of this pattern produces a latitudinally oriented center over the mid-latitudes of East Asia (Fig. 6b). Obviously, the positive anomaly center associated with an increase in its persistence is stronger than that associated with an increase in its frequency. Regarding the negative MOP pattern, increases in the frequency and persistence of this pattern are
Table 2. Correlation coefficients between the occurrence, frequency and persistence of each circulation pattern. The values from left to right are for the monopole (MOP), East Asia-Pacific (EAP) and southeast-northwest out-of-phase dipole (EWD) patterns, respectively. Bold type denotes statistical significance at the $99 \%$ confidence level

\begin{tabular}{|lcccccccc|}
\hline & \multicolumn{4}{c}{ Frequency- } & & \multicolumn{3}{c|}{ Persistence- -} \\
\cline { 2 - 4 } & MOP & EAP & EWD & & MOP & EAP & EWD \\
\hline Positive phase & & & & & & \\
Occurrence & $\mathbf{0 . 4 7 3}$ & $\mathbf{0 . 8 2 8}$ & $\mathbf{0 . 6 9 5}$ & $\mathbf{0 . 6 7 4}$ & $\mathbf{0 . 8 0 5}$ & $\mathbf{0 . 6 9 7}$ \\
Frequency & - & - & - & 0.043 & $\mathbf{0 . 4 9 4}$ & 0.200 \\
Negative phase & & & & & & \\
Occurrence & $\mathbf{0 . 8 7 4}$ & $\mathbf{0 . 5 1 5}$ & $\mathbf{0 . 9 0 8}$ & $\mathbf{0 . 8 0 0}$ & $\mathbf{0 . 7 3 2}$ & $\mathbf{0 . 7 7 5}$ \\
Frequency & - & - & - & $\mathbf{0 . 5 5 3}$ & 0.045 & $\mathbf{0 . 5 7 5}$ \\
\hline
\end{tabular}

linked to an obvious negative anomaly center over the mid-latitudes of East Asia (Fig. 6c,d). This negative anomaly center is much stronger when associated with the higher frequency of this pattern compared to that associated with its longer persistence.

For the positive MOP pattern, an anomalous anticyclonic circulation near Japan associated with its higher frequency enhances the easterly winds from the North Pacific, which then turn into southeasterly winds to northeastern China leading to above- 

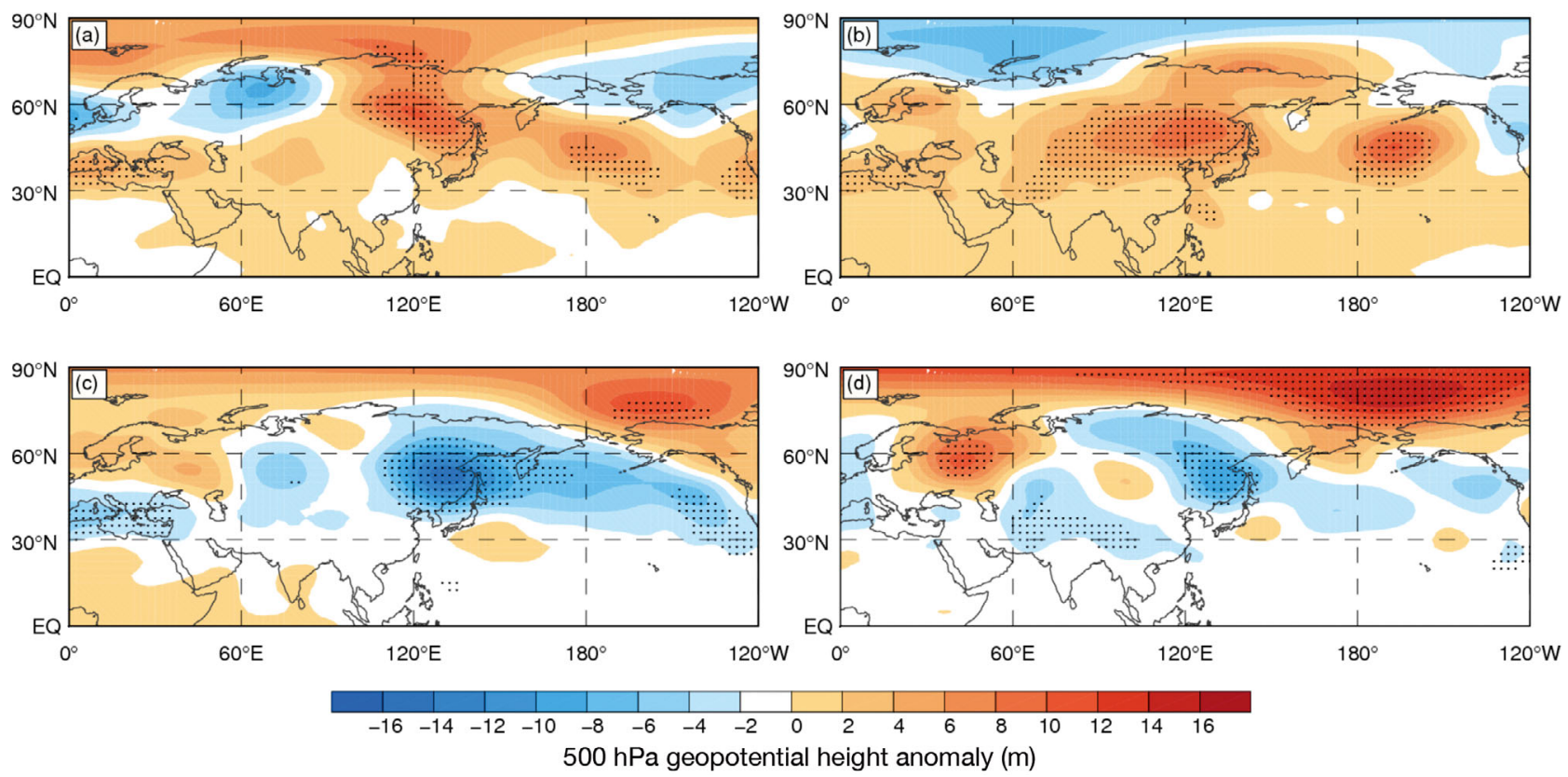

Fig. 6. Regression of the summer mean $500 \mathrm{hPa}$ geopotential height anomalies against the (a) frequency and (b) persistence in the positive phase of the monopole (MOP) pattern during 1961-2015. (c,d) As in (a,b), respectively, but in the negative phase of the MOP pattern. Dotted areas exceed the $95 \%$ confidence level using a 2-tailed Student's t-test

average precipitation in northeastern China (Figs. 7a \& 8a). In association with an increase in the persistence of this pattern, the anomalous anticyclonic circulation over the mid-latitudes of East Asia is conducive to the southward expansion of northerly flows, and the significant anomalous easterly winds from the western tropical Pacific to the Indian Ocean weaken the southerly water vapor transport associated with the summer monsoon winds (Fig. 7b). These conditions result in significantly above-average precipitation in the MLRYR, with below-average precipitation in northeastern China (Fig. 8b).

The anomalous Philippine cyclonic circulation associated with an increase in the frequency of the negative MOP pattern reduces the southerly water vapor transport from the SCS and western Pacific (Fig. 7C). Meanwhile, the anomalous cyclone in northeastern China and the anomalous anticyclone in southern Japan obviously weaken the northerly winds from high latitudes. These circulation conditions contribute to significantly below-average precipitation in northeastern and southern China (Fig. 8c). The anomalous Philippine cyclonic circulation associated with an increase in the persistence of the negative MOP pattern is much weaker than that associated with an increase in the frequency of this pattern, inducing insignificant impacts on precipitation in eastern China (Figs. $7 d \& 8 d$ ). This indicates that below-average precipitation in northeastern and southern China is primarily attributable to an increase in the frequency of this pattern.

\subsection{EAP pattern}

The EAP pattern mainly reflects the configuration of the WPSH, Mei-yu trough and Okhotsk high (Huang \& Li 1987, Huang 1992), and the location and strength of the 3 anomaly centers of the EAP pattern have considerable impacts on the persistent precipitation process in the Yangtze River valley (Li et al. 2018). For the positive EAP pattern, the $500 \mathrm{hPa}$ geopotential height anomalies associated with an increase in its frequency feature a tripole pattern over East Asia, with significant positive anomalies over the Sea of Okhotsk and western subtropical Pacific and negative anomalies in Japan. Clearly, the positive anomaly center over the Sea of Okhotsk associated with the higher frequency of this pattern is stronger than that associated with its longer persistence (Fig. 9a,b). For the negative EAP pattern, the negative anomaly center over the Sea of Okhotsk is much stronger when associated with its higher frequency compared to that associated with its longer persistence (Fig. 9c,d). Moreover, the longer persistence of this pattern produces strengthened positive anomalies near Japan. 

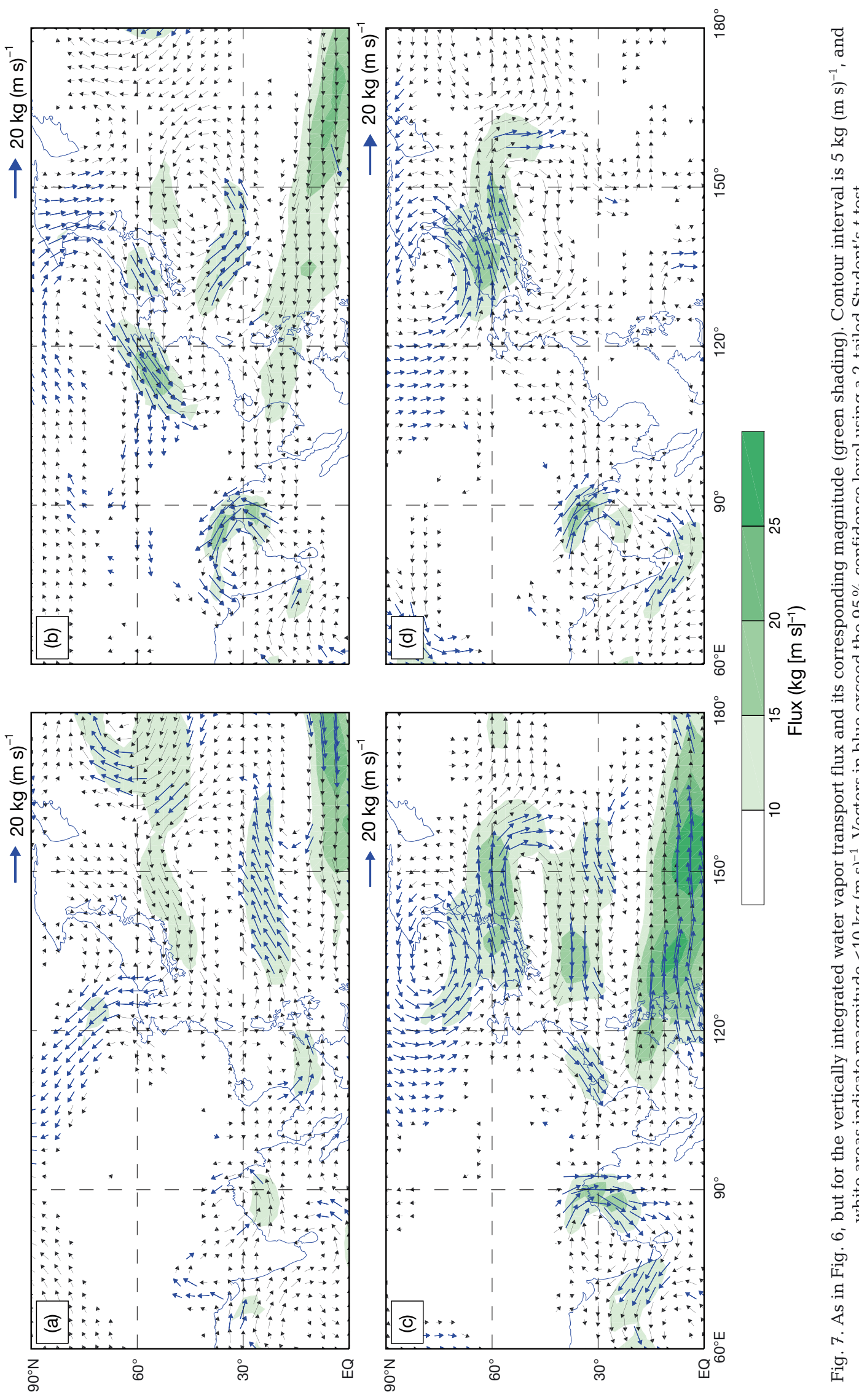

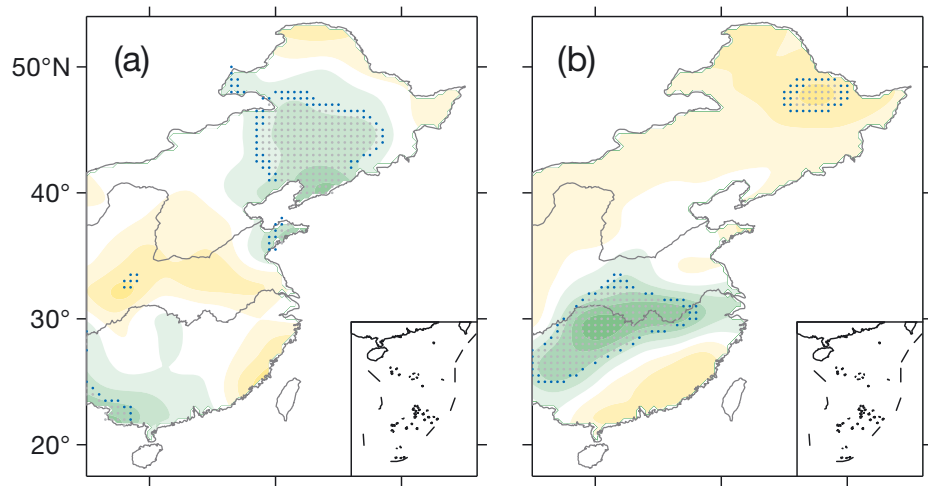

Precipitation $(\mathrm{mm})$
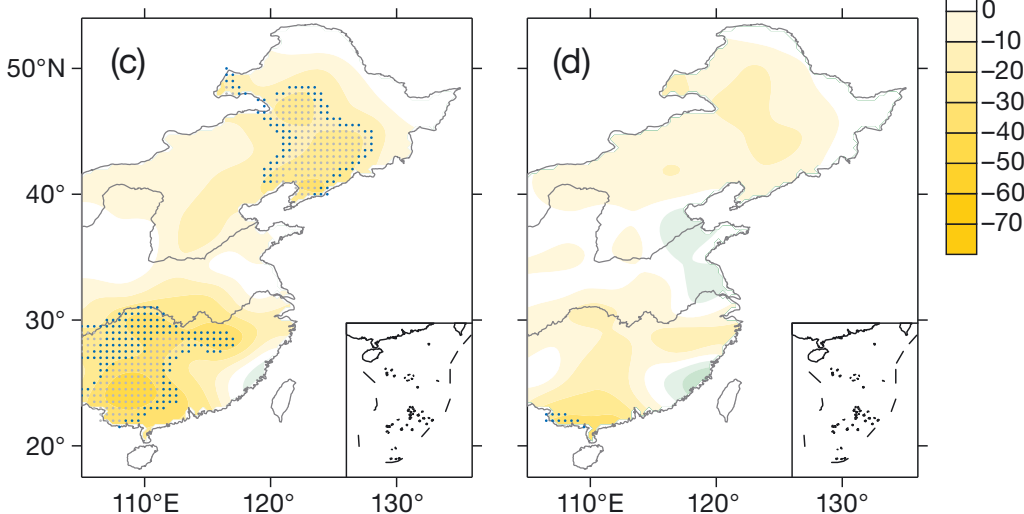

Fig. 8. As in Fig. 6, but for summer precipitation in eastern China. Blue and black dotted areas exceed the 90 and $95 \%$ confidence levels using a 2-tailed Student's $t$-test, respectively
On a climatological time scale, the positive EAP pattern enhances summer precipitation in the MLRYR (Huang et al. 2012); more precipitation tended to occur in this region before the late 1980s (Zhang 2015). On a synoptic time scale, the location and strength of the 3 EAP anomaly centers are directly related to different types of precipitation (Chen \& Zhai 2015). The southward movement of the EAP centers induces cold air to intrude in the lower latitudes and merge with southerly water vapor, leading to persistent precipitation in southern China (Li et al. 2018). Increases in the frequency and persistence of the positive EAP pattern produce an anticyclone-cycloneanticyclone circulation pattern over East Asia (Fig. 10a,b). The Philippine anticyclonic circulation is conducive to southerly water vapor transport from the SCS and the western Pacific to the MLRYR, which then merges with northerly flows transferred from the anomalous cyclone over the North Pacific. These circulation conditions lead to above-average precipitation in the MLRYR (Fig. 11a,b), which is consistent with the leading mode of summer
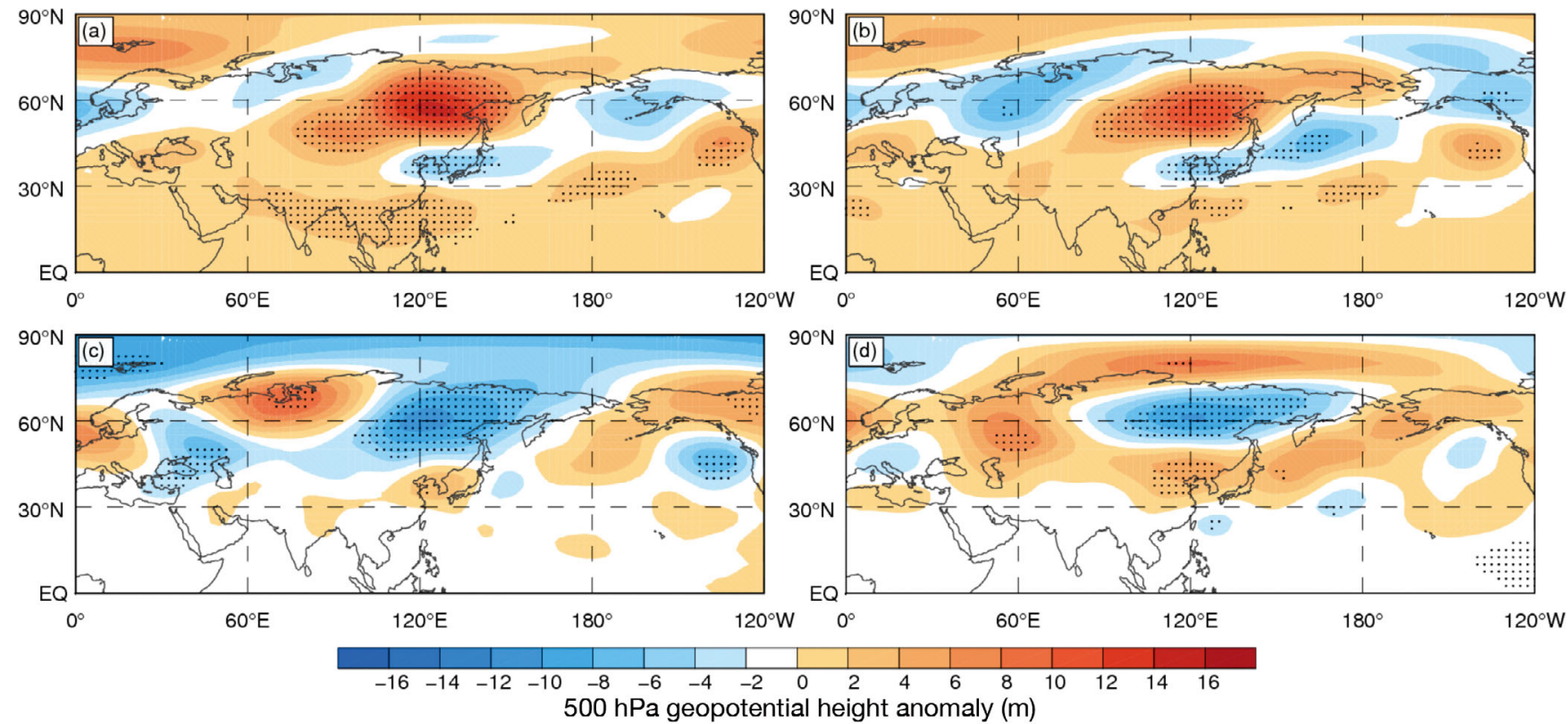

$500 \mathrm{hPa}$ geopotential height anomaly $(\mathrm{m})$

Fig. 9. Regression of the summer mean $500 \mathrm{hPa}$ geopotential height anomalies against the (a) frequency and (b) persistence in the positive phase of the East Asia-Pacific (EAP) pattern during 1961-2015. (c,d) As in (a,b), respectively, but in the negative phase of the EAP pattern. Dotted areas exceed the $95 \%$ confidence level using a 2-tailed Student's $t$-test 

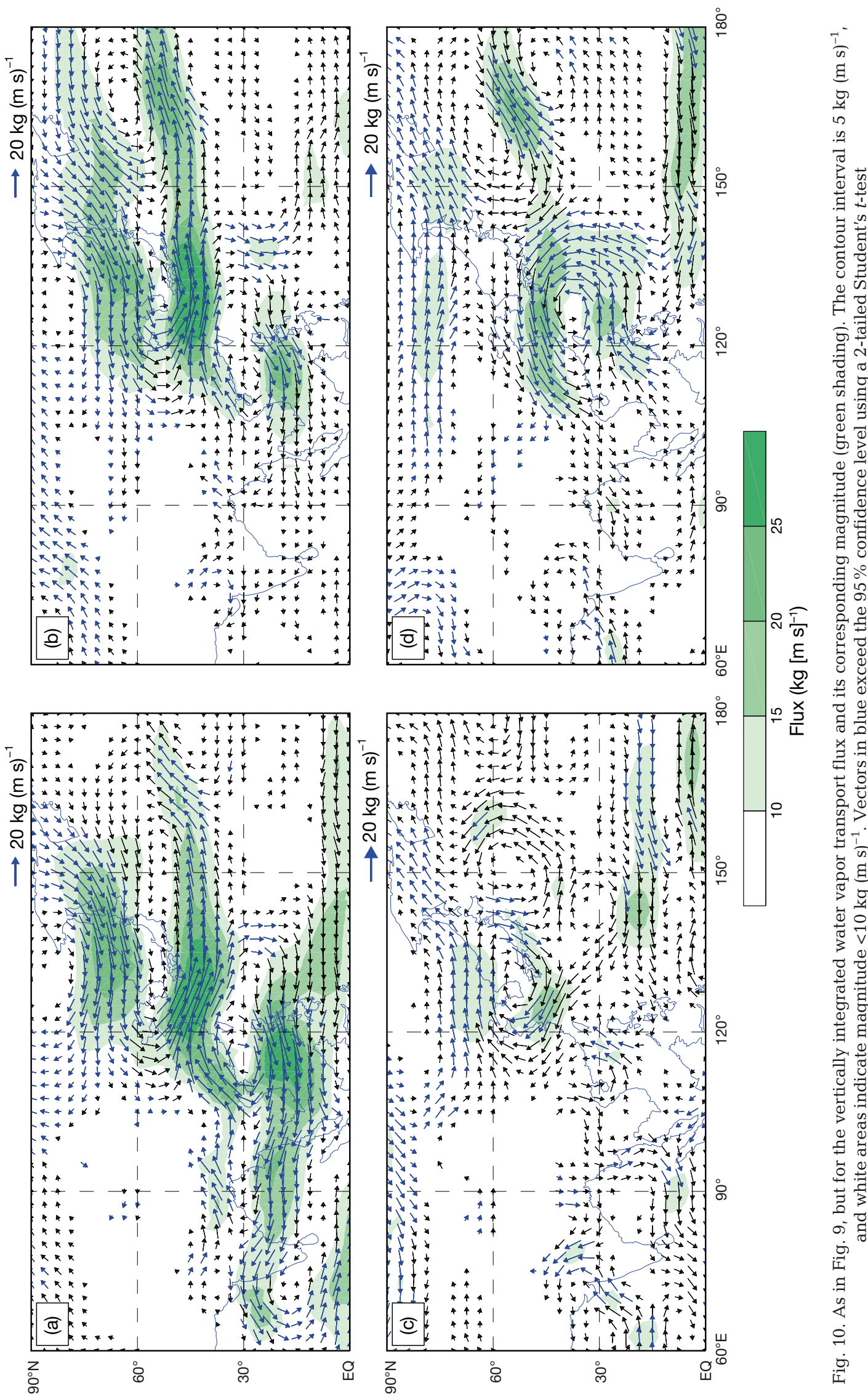
precipitation in eastern China (Chen et al. 2006). Compared to the higher frequency of this pattern, its longer persistence is more favorable for aboveaverage precipitation in the eastern region of the MLRYR

In association with increases in the frequency and persistence of the negative EAP pattern, the anomalous cyclonic circulation over the Philippine Sea reduces the southerly water vapor transport from the SCS and western Pacific to eastern China, and the anomalous anticyclonic circulation near Japan blocks southward expansion of the cold flows from high latitudes (Fig. 10c,d), both of which contribute to below-average precipitation in the MLRYR (Fig. 11c,d). Particularly, an increase in the frequency of this pattern strengthens anomalous anticyclonic circulation in southern Japan, resulting in above-average precipitation in northern China (Figs. 10c \& 11c). The longer persistence of this pattern favors below-average precipitation in northeastern China, as the anomalous Philippine cyclone is particularly strong and reduces the southerly water vapor transport from the tropics to eastern China (Figs. 10d \& 11d).
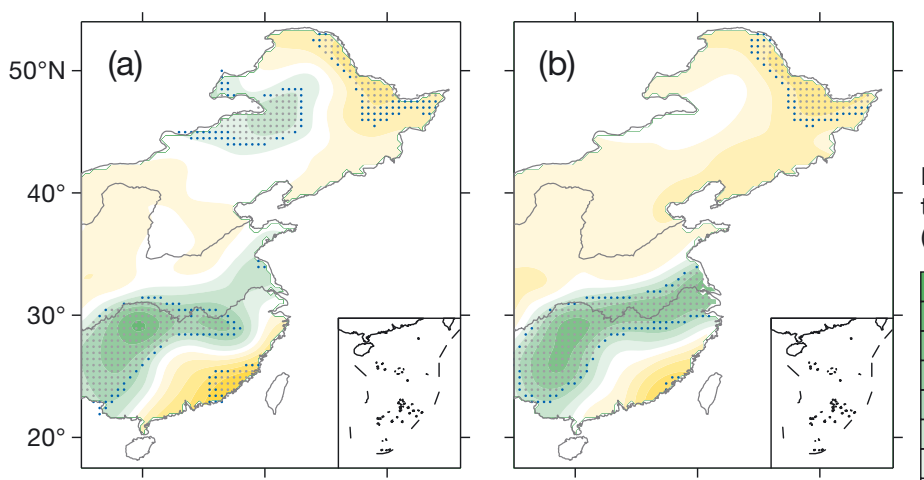

Precipitation $(\mathrm{mm})$
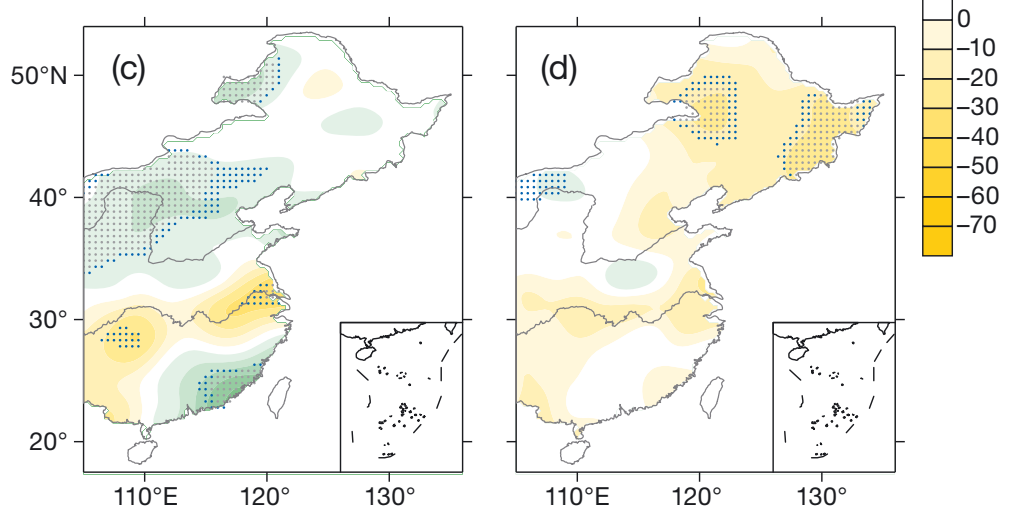

Fig. 11. As in Fig. 9, but for summer precipitation in eastern China. Blue and black dotted areas exceed the 90 and $95 \%$ confidence levels using a 2 tailed Student's $t$-test, respectively

\subsection{EWD pattern}

The 500 hPa geopotential height anomaly field features a wave train-like pattern over the mid-to-high latitudes of Eurasia, with 2 positive anomaly centers over Europe and northeastern Russia and 2 negative anomaly centers over the northern Atlantic and the Urals, when associated with increases in the frequency and persistence of the positive EWD pattern (Fig. 12a,b). In particular, the negative anomaly center over Japan associated with the higher frequency of the positive EWD pattern is much stronger than that associated with its longer persistence (Fig. 12a). Comparatively, increases in the frequency and persistence of the negative EWD pattern induce 2 positive anomaly centers over western Europe and the Urals and 2 negative anomaly centers over northern Europe and Mongolia (Fig. 12c,d). Moreover, the positive anomaly center in Japan associated with an increase in the negative EWD pattern persistence is stronger than that associated with an increase in the frequency of this pattern (Fig. 12d). These wave trainlike patterns resemble the EAWR teleconnection pattern, which is characterized by 4 anomaly centers, and extends across the Eurasian mainland (Barnston \& Livezey 1987, Wang et al. 2011). The impacts of the EAWR pattern on the climate reach the mid-latitudes of East Asia as a planetary-scale stationary wave pattern (Krichak et al. 2014), and the EAWR pattern is closely linked to summer precipitation over East Asia (Gao et al. 2017, Tan \& Shao 2017).

Regarding the positive EWD pattern, an increase in its frequency leads to anomalous northerly flows prevailing in eastern China and significant anomalous easterly winds from the Bay of Bengal to the western Pacific, reducing the northward propagation of southerly water vapor transport from the tropics and leading to below-average precipitation in northern China (Figs. 13a \& 14a). This result is consistent with that of Lin (2014), who reported that a positive EAWR pattern in summer causes an eastward retreat of the WPSH and then reduces precipitation in the subtropical East Asian rainy belt. In particular, an increase in the persistence of this pattern is favorable for aboveaverage precipitation in the MLRYR, where the anomalous southerly winds along the southern flank of the Tibetan Plateau merge with the anomalous northerly flows from high latitudes (Figs. 13b \& 14b). 

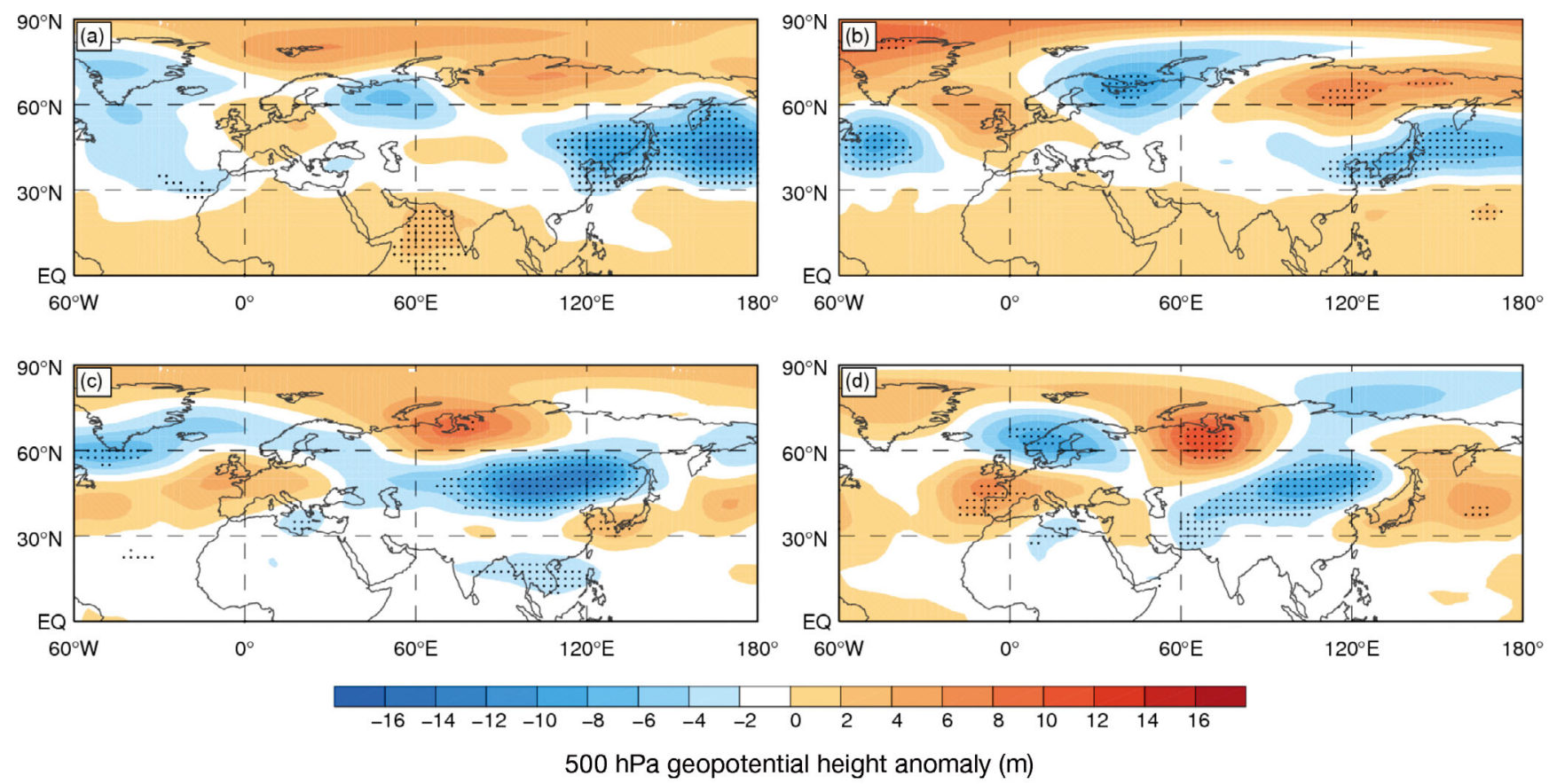

Fig. 12. Regression of the summer mean $500 \mathrm{hPa}$ geopotential height anomalies against the (a) frequency and (b) persistence in the positive phase of the southeast-northwest out-of-phase dipole (EWD) pattern during 1961-2015. (c,d) As in (a,b), respectively, but in the negative phase of the EWD pattern. Dotted areas exceed the $95 \%$ confidence level using a 2 -tailed Student's $t$-test

In association with increases in the frequency and persistence of the negative EWD pattern, the largescale anomalous anticyclonic circulation in eastern China enhances the southerly water vapor transport from the tropics, and the anomalous cyclonic circulation over Lake Baikal carries cold flows to northeastern China (Fig. 13c,d), resulting in above-average precipitation in northeastern China and below-average precipitation in the MLRYR (Fig. 14c,d). Compared to an increase in the persistence of the negative EWD pattern, an increase in the frequency of this pattern induces much less precipitation in the MLRYR due to the strengthened southerly winds in eastern China.

\section{DISCUSSION AND CONCLUSIONS}

Summer circulation patterns over the mid-latitudes of East Asia (namely, MOP, EAP and EWD patterns) were investigated in this study, and we found that the frequency and persistence of each pattern have different effects on summer precipitation in eastern China. Regarding the positive MOP pattern, an increase in its frequency induces the anomalous easterly water vapor transport from the North Pacific and then leads to above-average precipitation in northeastern China. The longer persistence of this pattern induces significantly above-average precipitation in the MLRYR, where the northerly flows from high latitudes converge with the southerly winds from the tropics. For the negative MOP pattern, an increase in its frequency contributes to significantly belowaverage precipitation in northeastern and southern China due to the anomalous Philippine cyclone and the anomalous anticyclone in Japan. Moreover, the higher frequency of the negative MOP pattern makes a greater contribution to below-average precipitation in northeastern and southern China compared to the longer persistence of this pattern.

For increases in the frequency and persistence of the positive EAP pattern, the anomalous cyclonic circulation in Japan enhances northerly cold flows from high latitudes, and the anomalous Philippine anticyclone increases southerly water vapor transport from the tropics, causing above-average precipitation in the MLRYR. Importantly, an anomalous increase in precipitation in the eastern region of the MLRYR is attributable to a longer persistence of this pattern. In contrast, increases in the frequency and persistence of the negative EAP pattern favor below-average precipitation in the MLRYR. The higher frequency of the negative EAP pattern intensifies precipitation in northern China, while its longer persistence obviously reduces precipitation in northeastern China. 

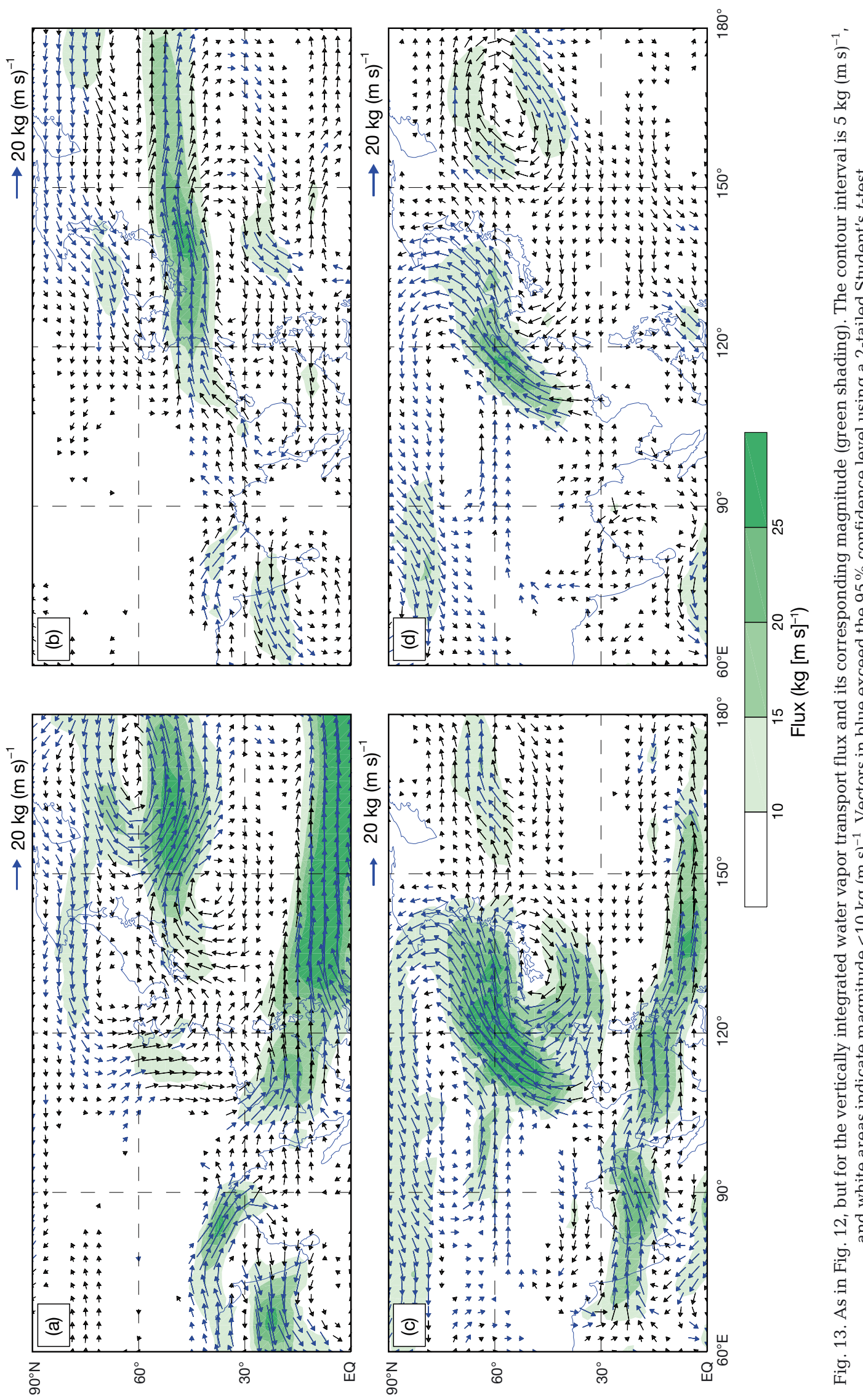

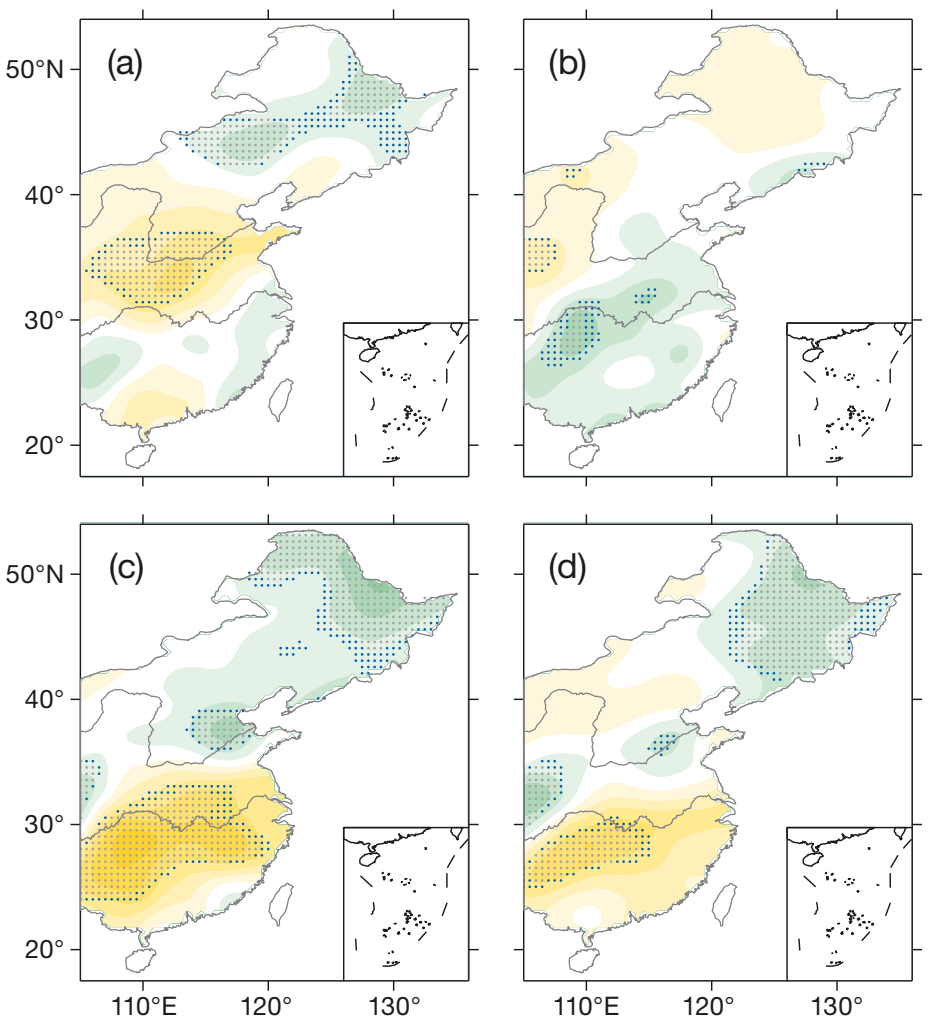

Fig. 14. As in Fig. 12, but for summer precipitation in eastern China. Blue and black dotted areas exceed the 90 and $95 \%$ confidence levels using a 2 tailed Student's $t$-test, respectively

An increase in the frequency of the positive EWD pattern produces the anomalous northerly winds in eastern China, leading to significantly below-average precipitation in northern China. The longer persistence of this pattern intensifies the southerly winds from the tropics, and therefore results in aboveaverage precipitation in the MLRYR. In contrast, the anomalous southerly winds prevailing in eastern China, and the anomalous cyclonic circulation in Mongolia, are beneficial for below-average precipitation in the MLRYR and above-average precipitation in northeastern China when associated with increases in the frequency and persistence of the negative EWD pattern. A remarkable decrease in precipitation in the MLRYR is attributable to the intensified anomalous southerly winds associated with an increase in the frequency of this pattern.

We found that the spring NAO is significantly correlated with the frequency of the negative MOP pattern. Previous studies have made much effort to investigate the connections between the NAO and the climate over East Asia (e.g. Watanabe 2004, Bollasina \& Messori 2018). The spring NAO imprints its signals on the North Atlantic summer sea surface temperature anomalies and then triggers a baro-
Precipitation $(\mathrm{mm})$

tropic teleconnection pattern over the North Atlantic and Eurasia, which is closely linked to the East Asian summer monsoon (Zuo et al. 2013). Jin \& Guan (2017) showed that the positive NAO induces an anomalous upper-level divergence in the Mediterranean, which excites the eastward propagation of the Rossby wave. We do not address the internal physical mechanisms between the spring NAO and MOP patterns any further in this study, and this might be a topic for future research.

The correlation coefficient between the May-July AO and the persistence of the positive EWD pattern was -0.45 , which is statistically significant at the $95 \%$ confidence level. The AO is a primary mode of atmospheric variability over the extratropics of the Northern Hemisphere, and is significantly connected to the atmospheric circulations over the mid-to-lower latitudes (Park et al. 2011, Dai \& Tan 2017). Chen et al. (2015) indicated that the influence of the spring $\mathrm{AO}$ on the following East Asian summer monsoon became obvious and significant during the mid-1970s to mid-1990s. The possible mechanisms linking the AO and EWD pattern deserve further investigation in the future.

Acknowledgements. We thank the China Meteorological Administration for providing the monthly precipitation data in China and the NCEP/NCAR for the daily and monthly reanalysis data. We also thank the reviewers for their constructive comments and suggestions, which led to significant improvements in the manuscript. This research was financially supported by the National Natural Science Foundation of China (Grant Nos. 41530531 and 41675092).

\section{LITERATURE CITED}

Barnston AG, Livezey RE (1987) Classification, seasonality and persistence of low-frequency atmospheric circulation patterns. Mon Weather Rev 115:1083-1126

*Barriopedro D, Gouveia CM, Trigo RM, Wang L (2012) The 2009/10 drought in China: possible causes and impacts on vegetation. J Hydrometeorol 13:1251-1267

*Bllasina MA, Messori G (2018) On the link between the subseasonal evolution of the North Atlantic Oscillation and East Asian climate. Clim Dyn 51:3537-3557

Chen HW, Zhang FQ, Alley RB (2016) The robustness of mid-latitude weather pattern changes due to Arctic seaice loss. J Clim 29:7831-7849

Chen JP, Wen ZP, Wu RG, Wang X, He C, Chen ZS (2017) An interdecadal changes in the intensity of interannual variability in summer rainfall over southern China around early 1990s. Clim Dyn 48:191-207 
Chen SF, Chen W, Wu RG (2015) An interdecadal change in the relationship between boreal spring Arctic Oscillation and the East Asian summer monsoon around the early 1970s. J Clim 28:1527-1542

Chen W, Kang LH, Wang D (2006) The coupling relationship between summer rainfall in China and global sea surface temperature. Clim Environ Res 11:259-269 (in Chinese)

* Chen Y, Zhai PM (2014) Precursor circulation features for persistent extreme precipitation in central-eastern China. Weather Forecast 29:226-240

Chen Y, Zhai PM (2015) Synoptic-scale precursors of the East Asia/Pacific teleconnection pattern responsible for persistent extreme precipitation in the Yangtze River valley. QJR Meteorol Soc 141:1389-1403

Cressman GP (1959) An operational objective analysis scheme. Mon Weather Rev 87:367-374

Dai PX, Tan BK (2017) The nature of the Arctic Oscillation and diversity of the extreme surface weather anomalies it generates. J Clim 30:5563-5584

Diao YN, Xie SP, Luo D (2015) Asymmetry of winter European surface air temperature extremes and the North Atlantic Oscillation. J Clim 28:517-530

*Ding YH (1992) Summer monsoon rainfalls in China. J Meteorol Soc Jpn 70:373-396

* Duckstein L, Bárdossy A, Bogárdi I (1993) Linkage between the occurrence of daily atmospheric circulation patterns and floods: an Arizona case study. J Hydrol (Amst) 143: 413-428

Gao T, Yu JY, Peak H (2017) Impacts of four Northern Hemisphere teleconnection patterns on atmospheric circulations over Eurasia and the Pacific. Theor Appl Climatol 129:815-831

Honda M, Inoue J, Yamane S (2009) Influence of low Arctic sea-ice minima on anomalously cold Eurasian winters. Geophys Res Lett 36:L08707

*Horton DE, Johnson NC, Singh D, Swain DL, Rajaratnam B, Diffenbaugh NS (2015) Contribution of changes in atmospheric circulation patterns to extreme temperature trends. Nature 522:465-469

Huang G (2004) An index measuring the interannual variation of the East Asian summer monsoon - the EAP index. Adv Atmos Sci 21:41-52

Huang RH (1992) The East Asia/Pacific pattern teleconnection of summer circulation and climate anomaly in East Asia. J Meteorol Res 6:25-36

Huang RH, Li WJ (1987) Influence of the heat source anomaly over the western tropical Pacific on the subtropical high over East Asia. In: Proc Int Conf General Circulation of East Asia, Chengdu, 10-15 April 1987, p 40-51

Huang RH, Cai RS, Chen JL, Zhou LT (2006) Interdecadal variation of drought and flooding disasters in China and their associated with the East Asian climate system. Chin J Atmos Sci 30:730-743 (in Chinese)

* Huang RH, Chen JL, Wang L, Lin ZD (2012) Characteristics, processes and causes of the spatio-temporal variabilities of the East Asian monsoon system. Adv Atmos Sci 29: 910-942

Jin DC, Guan ZY (2017) Summer rainfall seesaw between Hetao and the middle and lower reaches of Yangtze River and its relationship with North Atlantic oscillation. J Clim 30:6629-6643

Kalnay E, Kanamitsu M, Kistler R, Collins W and others (1996) The NCEP/NCAR 40-year reanalysis project. Bull Am Meteorol Soc 77:437-471
Krichak SO, Breitgand JS, Gualdi S, Feldstein SB (2014) Teleconnection-extreme precipitation relationships over the Mediterranean region. Theor Appl Climatol 117: 679-692

KYyselý J (2007) Implications of enhanced persistence of atmospheric circulation for the occurrence and severity of temperature extremes. Int J Climatol 27:689-695

Ki MX, Zhang QH, Zhang FQ (2016) Hail day frequency trends and associated atmospheric circulation patterns over China during 1960-2012. J Clim 29:7027-7044

KLi H, Zhai PM, Chen Y, Lu E (2018) Potential influence of the East Asia-Pacific teleconnection pattern on persistent precipitation in South China: implications of atypical Yangtze River valley cases. Weather Forecast 33:267-282

K Lin ZD (2014) Intercomparison of the impacts of four summer teleconnections over Eurasia on East Asian rainfall. Adv Atmos Sci 31:1366-1376

Lin ZH, Wang HJ, Zhou GQ, Chen H, Lang XM, Zhao Y, Zeng QC (2004) Recent advances in dynamical extraseasonal to annual climate prediction at IAP/CAS. Adv Atmos Sci 21:456-466

* Liu YM, Wu GX (2004) Progress in the study on the formation of the summertime subtropical anticyclone. Adv Atmos Sci 21:322-342

* Liu HC, Duan KQ, Li M, Shi PH, Yang JH, Zhang X, Sun JY (2015) Impact of the North Atlantic Oscillation on the dipole oscillation of summer precipitation over the central and eastern Tibetan Plateau. Int J Climatol 35: 4539-4546

Luo D, Xiao Y, Yao Y, Dai A, Simmonds I, Franzke CLE (2016) Impact of Ural blocking on winter warm Arcticcold Eurasian anomalies. I. Blocking-induced amplification. J Clim 29:3925-3947

* Ma ZG, Fu CB (2006) Some evidence of drying trend over northern China from 1951 to 2004. Chin Sci Bull 51: 2913-2925

Nitta T (1987) Convective activities in the tropical western Pacific and their impact on the Northern Hemisphere summer circulation. J Meteorol Soc Jpn 65:373-390

* Notaro M, Wang WC, Gong W (2006) Model and observational analysis of the Northeast US regional climate and its relationship to the PNA and NAO patterns during early winter. Mon Weather Rev 134:3479-3505

* Park TW, Ho CH, Yang S (2011) Relationship between the Arctic Oscillation and cold surges over East Asia. J Clim 24:68-83

* Petrow T, Zimmer J, Merz B (2009) Changes in the flood hazard in Germany through changing frequency and persistence of circulation patterns. Nat Hazard Earth Sys 9:1409-1423

Pokam WM, Djiotang LAT, Mkankam FK (2012) Atmospheric water vapor transport and recycling in Equatorial Central Africa through NCEP/NCAR reanalysis data. Clim Dyn 38:1715-1729

Ren BH, Lu RY, Xiao ZN (2004) A possible linkage in the inter-decadal variability of rainfall over North China and the Sahel. Adv Atmos Sci 21:699-707

* Ren X, Yang XQ, Sun X (2013) Zonal oscillation of western Pacific subtropical high and subseasonal SST variations during Yangtze persistent heavy rainfall events. J Clim 26:8929-8946

Screen JA, Simmonds I (2014) Amplified mid-latitude planetary waves favour particular regional weather extremes. Nat Clim Chang 4:704-709

* Smirnov VV, Moore GWK (1999) Spatial and temporal struc- 
ture of atmospheric water vapor transport in the Mackenzie River basin. J Clim 12:681-696

Spath H (1985) Cluster dissection and analysis: theory, FORTRAN programs, examples. Horwood, Chichester

Sun W, Yu RC, Li J, Yuan WH (2015) Three-dimensional circulation structure of summer heavy rainfall in central North China. Weather Forecast 30:238-250

Swain DL, Horton DE, Deepti S, Diffenbaugh NS (2016) Trends in atmospheric patterns conducive to seasonal precipitation and temperature extremes in California. Sci Adv 2:e1501344

Tan XZ, Shao DG (2017) Precipitation trends and teleconnections identified using quantile regressions over Xinjiang, China. Int J Climatol 37:1510-1525

Tao SY, Xu SY (1962) Circulation characteristics in association with persistent summer drought and flood in the Yangtze-Huaihe River reaches. Acta Meteorol Sin 32: 1-18 (in Chinese)

Wallace JM, Gutzler DS (1981) Teleconnections in the geopotential height field during the Northern Hemisphere winter. Mon Weather Rev 109:784-812

Wang L, Chen W (2014) East Asian winter monsoon: reamplification in the mid-2000s. Chin Sci Bull 59:430-436

Wang L, Gu W (2016) The eastern China flood of June 2015 and its cause. Sci Bull (Beijing) 61:178-184

Wang X, Wang CZ, Zhou W, Wang DX, Song J (2011) Teleconnected influence of North Atlantic sea surface temperature on the El Niño onset. Clim Dyn 37:663-676

Wang JB, Wen ZP, Wu RG, Guo YY, Chen ZS (2016) The mechanism of growth of the low-frequency East AsiaPacific teleconnection and the triggering role of tropical intraseasonal oscillation. Clim Dyn 46:3965-3977

Watanabe M (2004) Asian jet waveguide and a downstream extension of the North Atlantic Oscillation. J Clim 17: 4674-4691

Editorial responsibility: Ricardo Trigo,

Lisbon, Portugal
Wise EK, Dannenberg MP (2014) Persistence of pressure patterns over North America and the North Pacific since AD 1500. Nat Commun 5:4912

WW RG (2002) A mid-latitude Asian circulation pattern in boreal summer and its connection with the Indian and East Asian summer monsoons. Int $\mathrm{J}$ Climatol 22: 1879-1895

Xie ZW, Bueh CL (2015) Different types of cold vortex circulations over Northeast China and their weather impacts. Mon Weather Rev 143:845-863

Fang Q, Ma ZG, Fan XG, Yang ZL, Xu ZF, We PL (2017) Decadal modulation of precipitation patterns over eastern China by sea surface temperature anomalies. J Clim 30:7017-7033

Zhai PM, Zhang XB, Wan H, Pan XH (2005) Trends in total precipitation and frequency of daily precipitation extremes over China. J Clim 18:1096-1108

Z Zhang RH (2015) Changes in East Asian summer monsoon and summer rainfall over eastern China during recent decades. Sci Bull (Beijing) 60:1222-1224

Zhang QY, Tao SY (1998) Influence of Asian mid-high latitude circulation on east Asian summer rainfall. Acta Meteorol Sin 56:199-211 (in Chinese)

Zhang JK, Tian WS, Chipperfield MP, Xie F, Huang JL (2016) Persistent shift of the Arctic polar vortex towards the Eurasian continent in recent decades. Nat Clim Chang 6:1094-1099

* Zhou W, Chan JCL, Chen W, Ling J, Pinto JG, Shao YP (2009) Synoptic-scale controls of persistent low temperature and icy weather over southern China in January 2008. Mon Weather Rev 137:3978-3991

* Zuo JQ, Li WJ, Sun CH, Xu L, Ren HL (2013) Impact of the North Atlantic sea surface temperature tripole on the East Asian summer monsoon. Adv Atmos Sci 30: 1173-1186

Submitted: September 4, 2017; Accepted: November 16, 2018 Proofs received from author(s): July 7, 2019 